\title{
Ocorrência documentada de Formicivora grisea (Boddaert, 1783) (Aves: Thamnophilidae) na Área de Proteção Ambiental Delta do Parnaíba
}

Anderson Guzzi*, Deimes do Nascimento Gomes, Antonio Alves Tavares, Cleiton Oliveira Cardoso, Mário Sérgio Duarte Branco, Antonio Gildo Soares dos Santos

\section{Resumo}

Formicivora grisea (Boddaert, 1783) (Aves: Thamnophilidae), popularmente conhecida como papa-formiga-pardo, é comum no Brasil, ocorrendo desde a Amazônia até o Brasil Oriental em bordas de florestas úmidas e secas, capoeiras, restingas, caatingas e matas secundárias. Segue bandos mistos e, ocasionalmente, formigas de correição (Insecta: Hymenoptera: Formicidae). $\bigcirc$ presente estudo apresenta registro documentado e anilhamento de dois indivíduos dessa espécie no litoral do Piauí. Os exemplares, uma fêmea e um macho, foram capturados com redes de neblina durante esforço amostral em área de restinga com elementos de Cerrado e Caatinga com o objetivo de caracterizar e inventariar a avifauna daquele ecossistema situada próximo ao Aeroporto Internacional de Parnaíba, no dia 12/IX/2010.

Palavras-chave: Anilhamento,captura, papa-formiga-pardo, redes de neblina

\section{Documented occurrence of Formicivora grisea (Boddaert, 1783)}

(Aves: Thamnophilidae) in spits

\begin{abstract}
Formicivora grisea (Boddaert, 1783) (Aves: Thamnophilidae), popularly known as white-fringed antwren, is a common species in Brazil, occurring from the Amazon to eastern part of this country, living in the edges of wet and dry forests, secondary forest, capoeira and Restinga Forest, Caatinga Forest and secondary forest. This study presents a documented record and ringing of two individuals of this species on the coast of Piauí. The specimens, a female and a male, were captured with mist nets during sampling effort on a Restinga area with elements of Cerrado and Caatinga the aim of the avifauna characterization and inventory on the ecosystem situated near the International Airport of Parnaíba, Piauí, on 12/IX/2010..
\end{abstract}

Keywords: Formicivora grisea, Restinga Forest, captured, Parnaiba 
O gênero Formicivora Swainson, 1824 (Aves: Thamnophilidae) apresenta aves com um padrão geral do colorido de plumagem, que se assemelha a certos pássaros dos gêneros Drymophila Swainson, 1824 (Thamnophilidae) e Myrmotherula Sclater, 1858 (Thamnophilidae) ou ainda a algumas espécies do gênero Herpsilochmus Cabanis, 1847 (Thamnophilidae), os quais apresentam hábitos similares às espécies destes gêneros no comportamento geral, nos hábitos reprodutivos e na construção do ninho (Sigrist, 2009).

De acordo com O CBRO (2014) O gênero possui oito espécies, sendo quatro endêmicas do sudeste do Brasil ( $F$. iheringi Hellmayr, 1909, F. littoralis Gonzaga \& Pacheco, 1990, F. erythronotos (Hartlaub, 1852) e F. serrana (Hellmayr, 1829)) (Reis \& Gonzaga, 2000; del Hoyo et al., 2003).

A espécie F. grisea (Boddaert, 1783), popularmente conhecida como papa-formigapardo, possui $12 \mathrm{~cm}$, e no Brasil ocorre desde a Amazônia até o Brasil Oriental em bordas de florestas úmidas e secas, capoeiras, restingas, caatingas e matas secundarias. Segue bandos mistos e, ocasionalmente, formigas de correição
(Insecta: Hymenoptera: Formicidae). O macho de F. grisea distingue-se do de F. melanogaster Pelzeln, 1868, com o qual é sintópico, pelos tons cinza-amarronzados das partes superiores e não cinza-azulados presentes naquele (Sigrist, 2009).

Quanto ao status de conservação, a espécie aparece com grande abundância no Brasil, sendo que a tendência da população parece estável e, portanto, a espécie não se aproxima dos limiares de vulnerabilidade sob - critério de evolução demográfica (declínio > $30 \%$ em dez anos ou três gerações), ocorrendo na Bolívia, Brasil, Colômbia, Guiana Francesa, Guiana, Panamá, Suriname, Trinidad e Tobago e Venezuela (Birdlife, 2012).

Os exemplares, uma fêmea e um macho (Figuras 1 e 2), foram capturados com redes de neblina durante esforço amostral em área de restinga com o objetivo de caracterizar e inventariar a avifauna daquele ecossistema situado próximo (2053'16"S 4142'18"O) ao Aeroporto Internacional de Parnaíba, Piauí, no dia 12/IX/2010. O município de Parnaíba está situado na área litorânea piauiense, juntamente com outros três municípios: Ilha Grande, Luiz Correia e Cajueiro da Praia (IBGE, 2010).

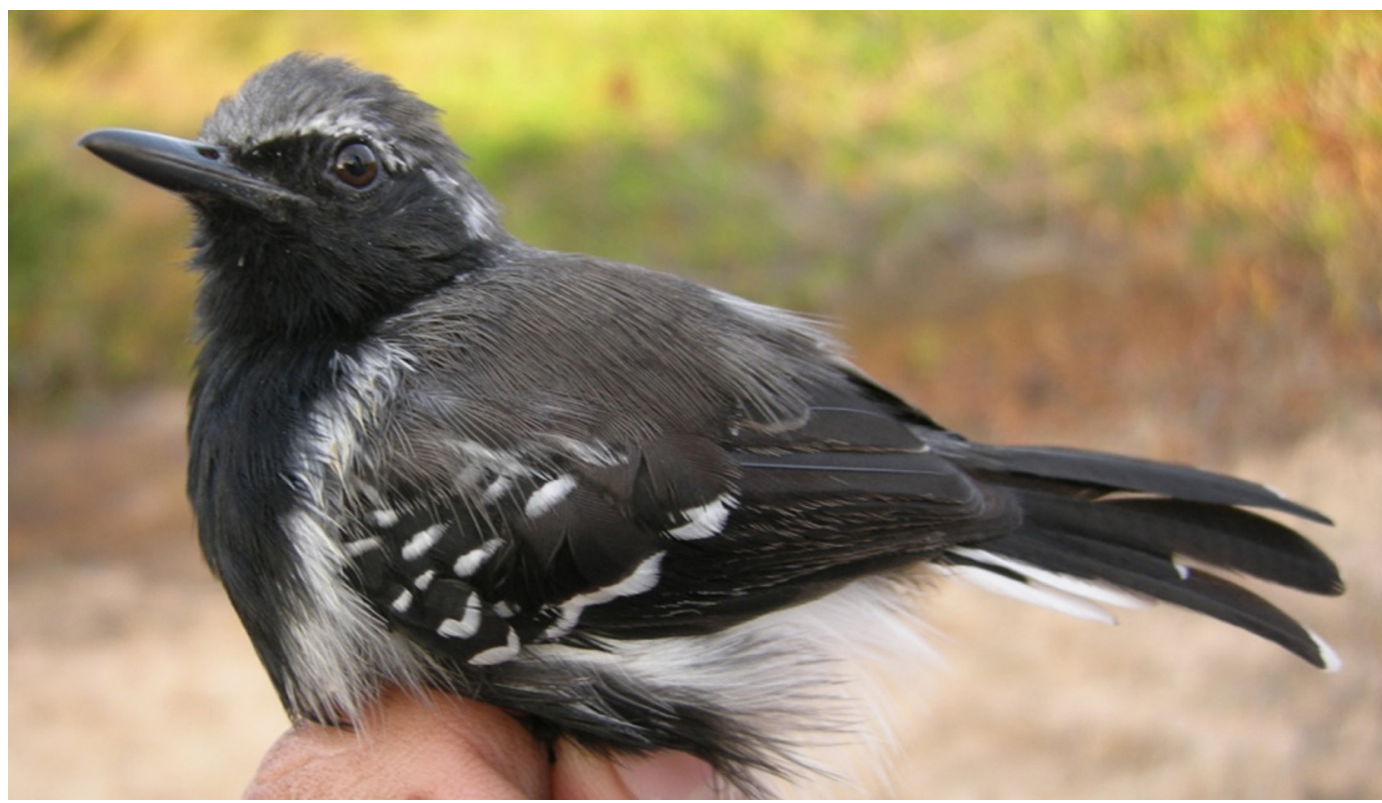

Figura 1. Formicivora grisea (Boddaert, 1783) (Aves: Thamnophilidae), macho, capturado em área de restinga, Parnaíba, Piauí, Brasil. 


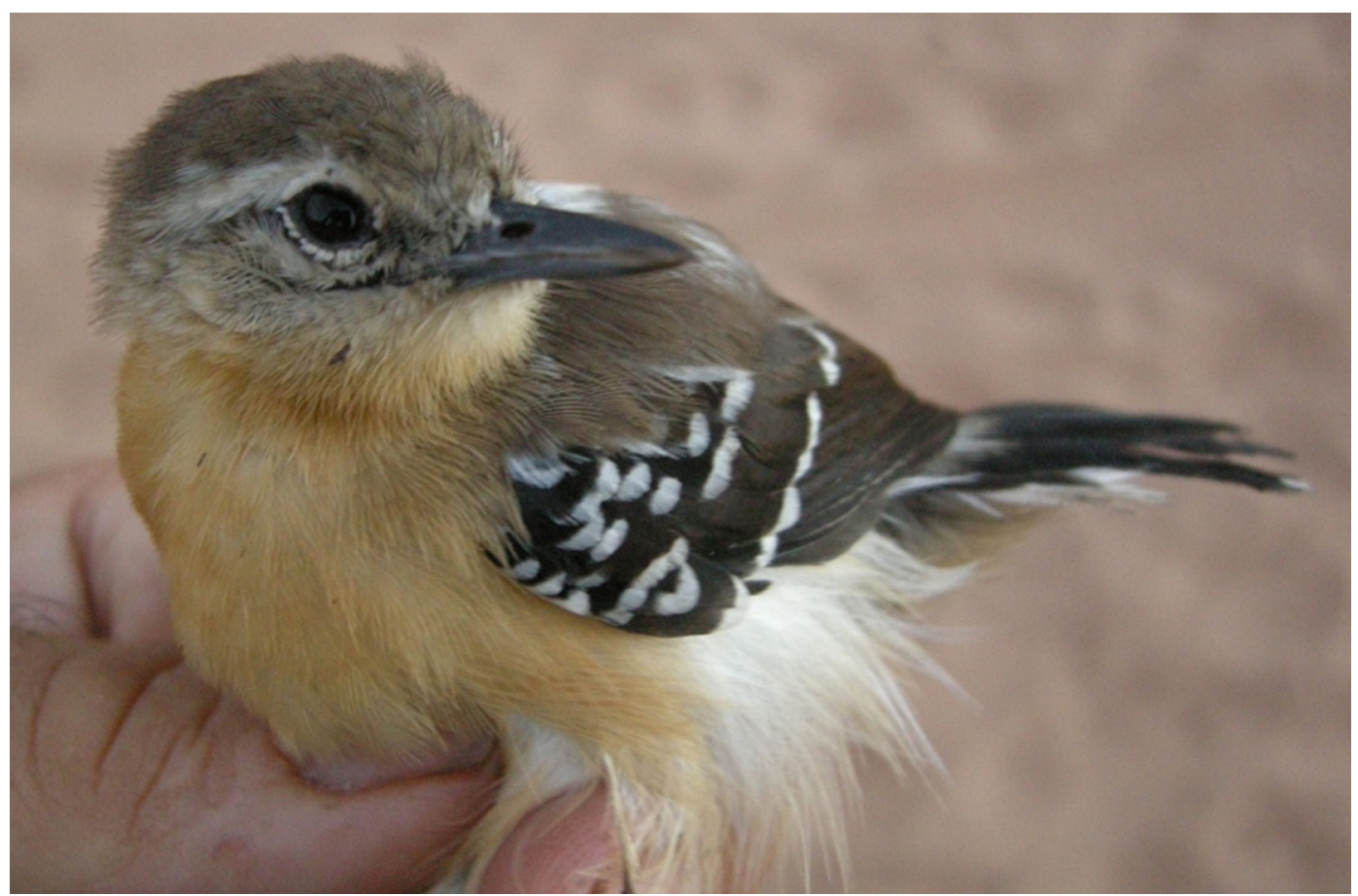

Figura 2. Formicivora grisea (Boddaert, 1783) (Aves: Thamnophilidae), fêmea, capturada em área de restinga, Parnaíba, Piauí, Brasil.

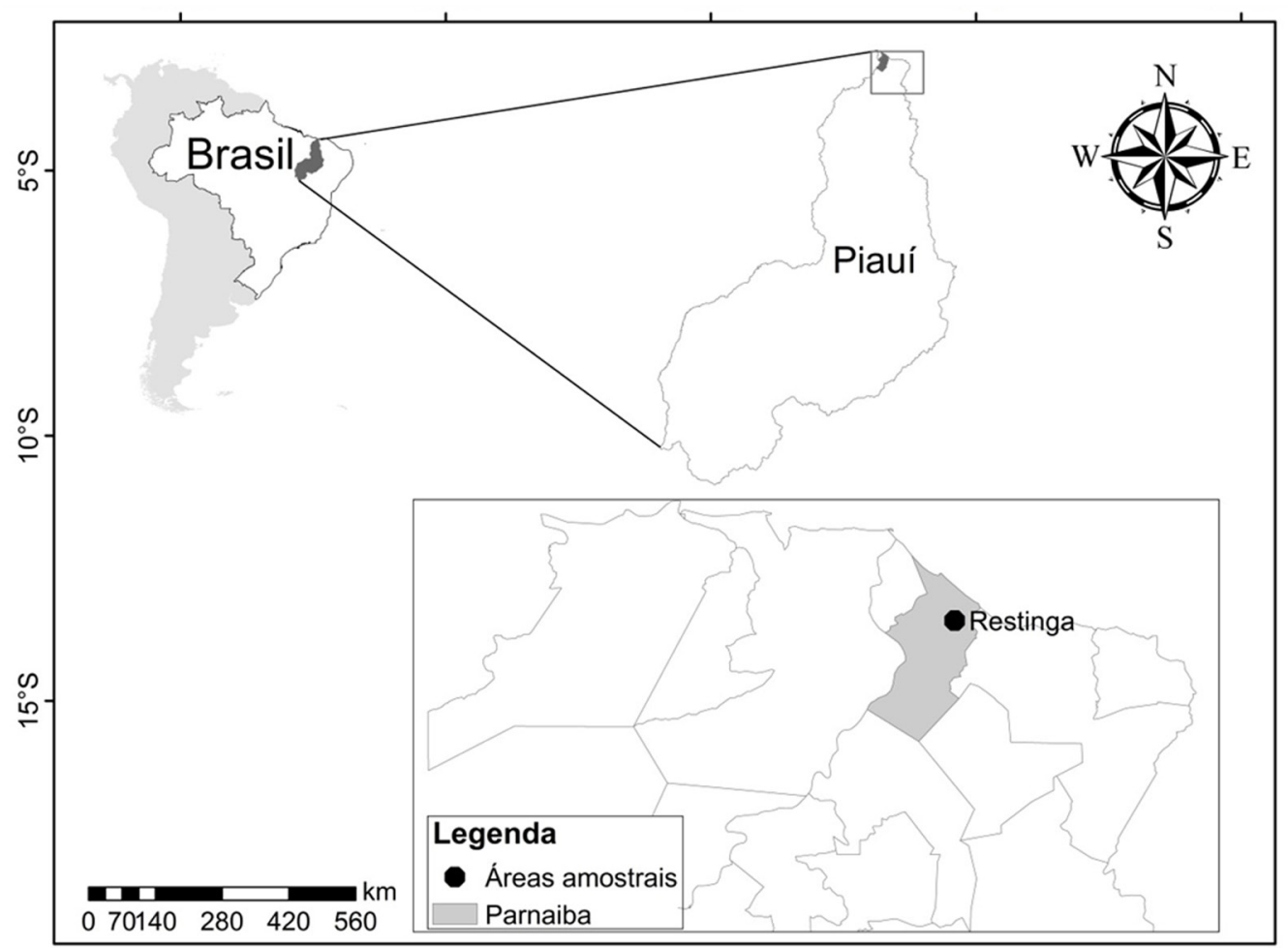

Figura 3. Mapa da região de estudo. 
Os espécimes foram capturados no período da manhã, foram anilhados com anilhas numeradas padrão CEMAVE (ICMBio). Os principais dados biométricos são: macho - comprimento total do corpo: $11,7 \mathrm{~cm}$; asa: $4,8 \mathrm{~cm}$; cauda: $4,2 \mathrm{~cm}$; comprimento do tarso: $1,6 \mathrm{~cm}$; peso: 8 g.; fêmea - comprimento total do corpo: $11 \mathrm{~cm}$; asa: $4,8 \mathrm{~cm}$; cauda: $4,2 \mathrm{~cm}$; comprimento do tarso: $1,7 \mathrm{~cm}$; peso: $9 \mathrm{~g}$. Os dois indivíduos eram adultos e estavam em período de muda, identificado pelos canhões nas asas.

A área amostral é composta por ambiente de restinga (Figura 3). Segundo Santos Filho et al. (2015) a restinga piauiense conta com cerca de 363 espécies pertencentes a 74 famílias botânicas, das quais $13 \%$ de lenhosas exclusivas às restingas estudadas. A forma de vida predominante $(57,6 \%)$ é a de nanofarenófitos, similar ao que ocorre entre outras restingas brasileiras. As famílias mais representativas são Fabaceae (108 spp.), Euphorbiaceae (19 spp.) e Amaranthacea (13 spp). Suas fisionomias são semelhantes às demais restingas brasileiras (campos, frutícetos e florestas). As espécies comuns a outras áreas são: Cyperus maritimus Poir (Cyperaceae), Matelea maritima (Jacq.) Woodson (Apocynaceae), entre outras. O bioma apresenta similaridade com as demais restingas nordestinas, intrinsecamente relacionadas à Floresta Atlântica em sua composição, do que com os ecossistemas a elas adjacentes.

\section{Referências}

Birdlife International. Formicivora grisea. The IUCN Red List of Threatened Species. Version 2014.2. 2012. http://www.iucnredlist.org/<Acesso em 09 Set. 2014>

Comitê Brasileiro de Registros Ornitológicos (CBRO). Lista de Aves do Brasil Versão 2014. 2014. http//www.cbro.org.br/<Acesso em $18 \mathrm{fev}$. 2014>

del Hoyo, J., Elliot, A., Christie, D.A. (eds.) 2003. Handbook of the birds of the world, vol. 8: Broadbills to Tapaculos. Lynx Edicions, Barcelona, Espanha. 845 p.

IBGE. Cidades. 2010. Instituto Brasileiro de Geografia e Estatística. http://www.ibge.gov. br/<Acesso em 09. Junho de 2015>

Reis, H.B.R., Gonzaga, L.P. 2000. Análise da distribuição geográfica das aves das restingas do estado do Rio de Janeiro. In: Esteves, F.A., Lacerda, L.D. (eds.) Ecologia de restingas e lagoas costeiras. NUPEM/UFRJ, Rio de Janeiro, Brasil. 165-178 p.

Santos-Filho, F.S., Almeida Jr., E.B., Lima, P.B., Soares, C.J.R.S. 2015. Checklist of the flora of the Restingas of Piauí state, Northeast Brazil. Check List, 11(2): 1-10.

Sigrist, T. 2009. Aves do Brasil: Uma Visão Artística. Editora Avis Brasilis, Vinhedo, Brasil. 600 p. 